\title{
Sudden death of an Arctic wolf population in Greenland
}

\author{
Ulf Marquard-Petersen ${ }^{1}$ \\ 'Greenland Wolf Research Program, Anchorage, AK, USA
}

\section{Abstract}

This study reports the disappearance of a small Arctic wolf population in north-east Greenland founded in 1979 and provides the first long-term information on the wolf packs of this region. Data sources comprised specialized wolf surveys in two of three distributional core areas during three summers, 2012-14, and incidental sightings of wolves by military ground patrols during winter and by others yearround. The resulting time series spans 40 years (1979-2018). After gradually increasing for 14 years, the sighting rate peaked in 1996 and then declined to zero after May 2002, suggesting that the population went extinct. The crash occurred despite year-round legal protection in a national park and resulted in a $51.2 \%$ reduction in the extent of the occupied wolf range in Greenland and a $41.8 \%$ reduction in Greenland's wolf population size. It was outside the scope of this study to conduct a complete analysis of all potential factors in the disappearance. In north Greenland, a small population of up to 32 wolves during optimal years continues to exist, and dispersers reach north-east Greenland occasionally. A number of measures are proposed that, if implemented by the Greenland Home Rule Government, would help secure the future of the few remaining wolves on the island.
\end{abstract}

\section{Keywords}

Canis lupus arctos; conservation; crash; disappearance; management; wolves

\section{Correspondence \\ Ulf Marquard-Petersen, Greenland Wolf Research Program, 5836 E. 10th Circle, Anchorage, AK 99504, USA. E-mail umpetersen1@hotmail.com}

\section{Abbreviations}

SD: standard deviation

\section{Introduction}

Changes in the distribution of species are happening globally (Pecl et al. 2017). Across the Arctic, caribou and reindeer (Rangifer tarandus) have been declining (Vors \& Boyce 2009). There is a paucity of data on the status of wolf (Canis lupus) populations in the High Arctic. In north-east Greenland, an Arctic wolf (C. l. arctos) population had been exterminated by commercial hunters by ca. 1939 (Marquard-Petersen 2012). For 40 years, no viable wolf population inhabited this region. Then, in 1979, a wolf pair from north Greenland recolonized north-east Greenland and founded a new population (MarquardPetersen 201 la). The new arrivals inhabited the Northeast Greenland National Park, where they received year-round legal protection. Wolves that later moved into areas outside the national park, such as Jameson Land, were not protected by law. The population increased during the 1980s, and by the early 1990s, up to 23 wolves inhabited north-east Greenland, primarily distributed in three core areas (Marquard-Petersen 2009, $201 \mathrm{lb}$ ). The wolf population in north-east Greenland was considered separate from that of north Greenland because of its history and geographical isolation due to vast areas of unsuitable wolf habitat between the two regions (see Marquard-Petersen 2011a). The primary prey of wolves in Greenland was muskox (Ovibos moschatus; Marquard-Petersen 1998).
Data from 1999, however, indicated that the number of sightings of wolves in north-east Greenland during winter was decreasing relative to previous years. By 2004, not a single wolf was seen by the Danish military personnel responsible for conducting sovereignty patrols in the region. During the following years, this absence of sightings continued, leading to my hypothesis of a regional wolf population crash in north-east Greenland. Because little was known about the frequency and amplitude of perturbations of wolf populations in the High Arctic, I set out to test that hypothesis in 2012 through a combination of field surveys, data collection and analysis. I predicted that the population had undergone either a gradual decline (e.g., slow decrease in population size over a number of years) or a sudden death (e.g., a population collapse occurring rapidly within a few years).

\section{Methods}

To investigate this wolf population, I used presence/ absence data compiled from 1979 to 2018. This method underestimates wolf abundance, because an absence of sightings only meant none was seen (see Krebs 1999). To compensate, I continued data collection well beyond the time the population apparently disappeared.

I used a combination of fieldwork and incidental wolf sightings reported by others to investigate population 
status at different spatial scales. I conducted specialized wolf surveys on foot during summer in two of the three distributional core areas: Jameson Land and Hold with Hope (Fig. 1). The goal was to establish whether wolves were present or absent. Field surveys were essential, because aerial surveys of wolves on the open tundra of the High Arctic provide misleading estimates (see Miller \& Russell 1977). Surveys consisted of line transects walked across the tundra, focusing on areas where ground conditions were favourable for detecting wolf tracks, for example, along rivers and streams or across mud flats. Transects could be up to $90 \mathrm{~km}$ long and were not randomly spaced. The intent was to cover as much country as possible in order to reduce the probability of making a type II error (failing to detect a species when in fact it is present). High ground mobility was important, because wolves in this region occurred at one of the lowest densities recorded: $\leq 1$ wolf/3745 $\mathrm{km}^{2}$ (MarquardPetersen 2009). Known wolf den sites were examined for recent evidence of wolves (excavations, scats, hair, beds, scratchings, prey remains) and muskox carcasses for signs of predation or scavenging by wolves (see Haynes 1982). Visitor logbooks in cabins used by military patrols, expeditions and others were examined. These logs typically covered decades and were valuable sources of information, because visitors frequently wrote down details on their stay, including wolf sightings, if any. Because I could not visit north-east Greenland every year, logs provided important snapshots in time of conditions during my absence but with limitations: whereas logs could indicate the presence of wolves, a lack of mention of wolf could not be considered as evidence of wolf absence.

A lack of services and remoteness made surveys in Germania Land impracticable. I did not consider fieldwork in Germania Land to be strictly necessary, however, because a weather station, Danmarkshavn, was located there. This facility was staffed year-round. It is well documented that Arctic wolves are attracted by weather stations, their garbage dumps and tethered sled dogs and that this attraction results in their detection (Grace 1976; Miller 1978; Gray 1995; Miller \& Reintjes 1995). Therefore, if wolves were present in this area, station personnel would be expected to know about it. I therefore repeatedly queried the station manager by e-mail.

I collected data on incidental wolf sightings by military ground patrols in 1979-2018. The Danish military conducted sovereignty patrols by dog team in early (October-December) and late (March-June) winter. A single patrol could last months and cover in excess of $1700 \mathrm{~km}$. These patrols can be considered line transects, with distance travelled a measure of search effort. The patrols adhered to some criteria associated with proper

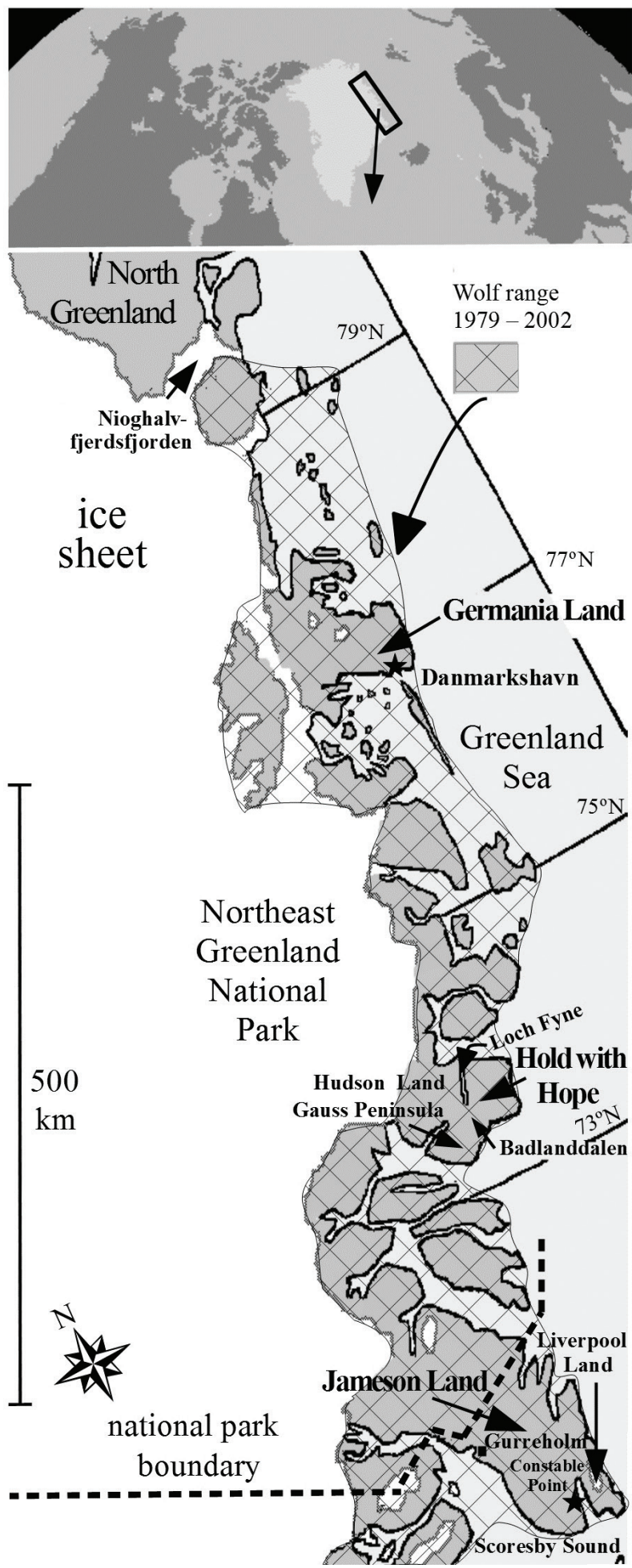

Fig. 1 Map of the study region in north-east Greenland showing areas of fieldwork, localities mentioned in the text and wolf range contraction reported here. Smaller map illustrates the extreme geographical isolation of the north-east Greenland wolf population. 
survey design. They were standardized, because personnel selection criteria and training were uniform and consistent, means of travel did not change and speed remained relatively constant. Routes were selected in a systematic rather than random fashion. Many of the same routes were used in most years, and all areas accessible by dog team were patrolled at least once every five years. Reports of wolves detected on or near the line of travel was certain under most conditions, because: (1) the men were under orders to report all sightings of wildlife, (2) the treeless terrain facilitated the detection of animals, (3) the presence of sled dogs and their superior olfactory and auditory senses increased the probability of detecting wolves during periods of inclement weather, and (4) the normal behaviour of Arctic wolves includes seeking out humans and their dogs (Riewe 1975; Miller 1978; Marquard-Petersen 201la). On the other hand, patrols violated a number of assumptions of unbounded line transects that precluded a rigorous statistical analysis, for example, angle/distance measurements were not recorded, and wolves were often detected moving towards the observer (see Krebs 1999). Nevertheless, sightings could be utilized as a simple index of population trend that was both logistically effective and noninvasive. After obtaining sightings of wolves and information on patrol effort, I standardized raw sightings as "wolves seen per $1000 \mathrm{~km}$ of linear surface travel" to correct for the possibility of fewer wolves being seen during some years on account of less travel. I calculated annual distances patrolled during 1979-1998 from maps provided by the military, showing travel routes. Distances during 1999-2018 were calculated by the military.

I analysed the data on two spatial scales. At the regional scale (north-east Greenland), I plotted number of wolves seen/1000 km by military patrols to examine the speed of the hypothesized decline and similar data from north Greenland to evaluate if a decline had also taken place there. At the local scale (wolf core areas), I plotted incidental sightings by all sources in the three distributional core areas in north-east Greenland. Regardless of data source, I censored the data to include only actual sightings of wolves, excluding reports of wolf tracks, because of concerns about reporters' ability to distinguish wolf tracks from those of other canids present in the region (domestic dogs, Arctic foxes [Alopex lagopus]). I included in the final data set from each local area only the maximum number of wolves sighted at any one time during each calendar year, because the wolves were not marked or instrumented, and an accurate count in each area was therefore difficult to achieve. I truncated known, or presumed, repeat observations of the same individual(s) and assumed that the resulting data set could serve as an indicator of the status of this wolf population. All data on wolf sightings were extracted from a database compiled by me, containing 783 sightings of wolves or their sign in Greenland, 1899-2018.

\section{Results}

Survey effort among areas was uneven, lasting between 8 and 35 days, depending upon terrain, ability to arrange favourable logistics and weather conditions that affected flying and landing conditions.

\section{Jameson Land}

Two surveys were completed in consecutive years. The first survey of 8-29 August 2012 (204 km) from Constable Point directly to Gurreholm and back did not penetrate as far as planned on account of difficult terrain. Because the military did not patrol Jameson Land, I returned to the area during 12 July-15 August 2013 to reduce the risk of a type II error. The second survey $(298 \mathrm{~km})$ also crossed Jameson Land but along a route farther inland, while adding a 98-km transect along the Schuchert River. No wolves were seen during either survey, and no wolf tracks were found despite excellent tracking conditions in sand and mud along the many rivers and streams and on mud flats along the coast of Scoresby Sound. A wolf den near Schuchert River was located and examined. Tunnels were collapsed and entrances overgrown; there were no signs of recent excavations, no wolf scats and no hair attributable to wolf.

Throughout Jameson Land, skeletal remains of muskoxen were found almost daily. With long bones scattered around the rest of the skeleton, they lay largely intact, having rested in situ for varying amounts of time as evidenced by different degrees of eutrophication. Skeletons of recent origin showed no evidence of the heavy utilization that I had observed elsewhere in Greenland when wolves were present. Data from expeditions, hunters and others indicated that the Arctic wolf was sighted in Jameson Land during at least 14 of 17 years, 1982-98 (Fig. 2).

\section{Hold with Hope}

The planned survey in this area was unexpectedly cut short by logistical difficulties and an $80 \%$ snow cover on 1 July followed by heavy rain that prevented landing on an 


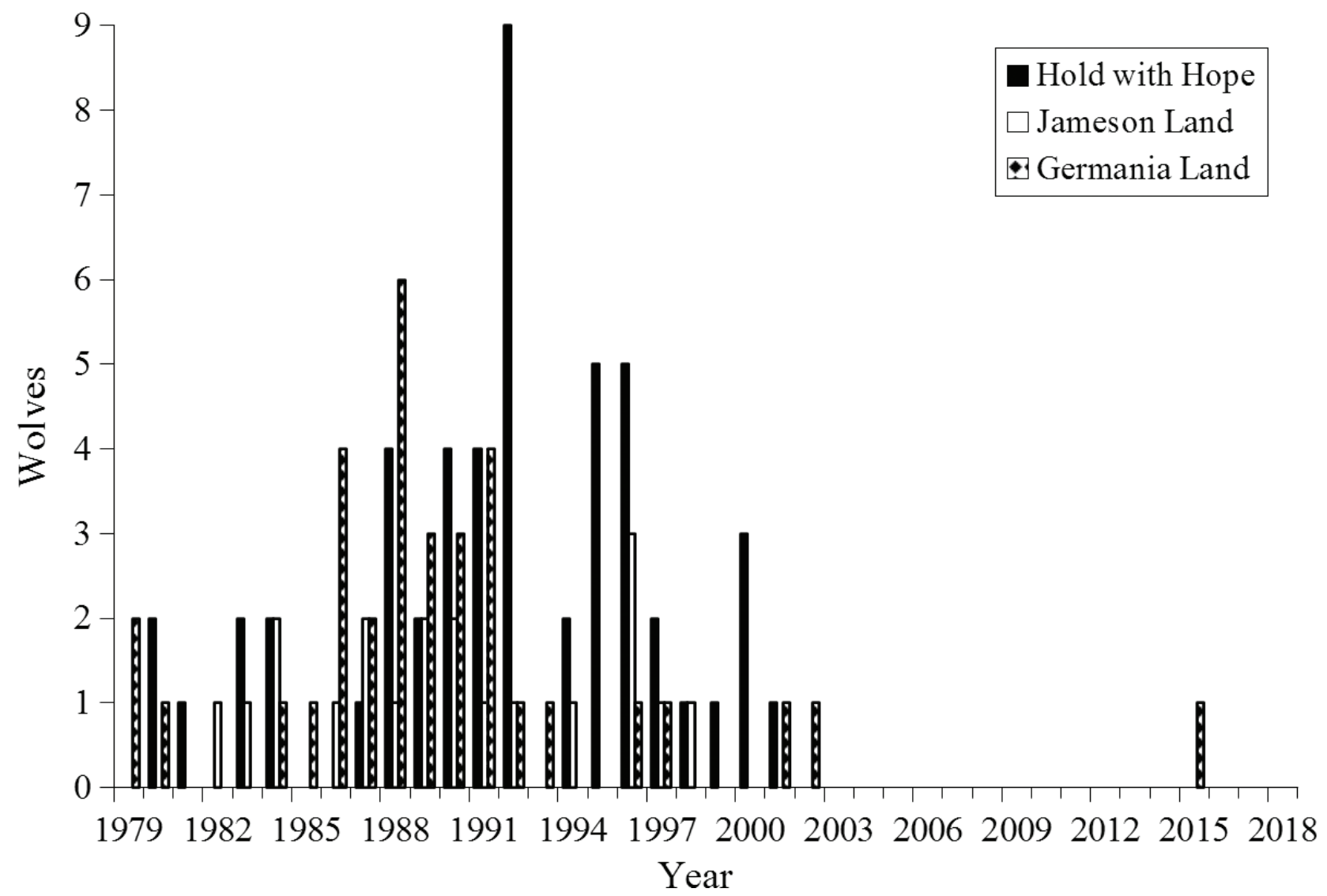

Fig. 2 The decline of wolves on a local scale. Largest group sizes sighted in distributional core areas in north-east Greenland, 1979-2018. All areas show evidence of local declines to extinction after group sizes reached maximum values.

improvised (now water-logged) tundra air strip until the latter half of July. During 22-29 July 2014, the survey team walked a total of $77 \mathrm{~km}$, including two transects through the valley named Badlanddalen. The first transect $(26 \mathrm{~km})$ extended from the Stordal landing strip directly across the valley and then south to the former weather station Myggbukta. The second transect $(23 \mathrm{~km})$ extended up the middle of the valley from the Greenland Sea to the head of Loch Fyne. Side trips were made to Vestersletten and along Loch Fyne. No wolves or wolf tracks were found despite some of the best tracking conditions in north-east Greenland: animal tracks were easily detectable. Locations where I had recorded wolf tracks during the summers of 1992-94, 1996 and 1998 were now devoid of tracks. The four known den sites occupied by wolves in previous years had collapsed tunnels and overgrown entrances, without evidence of recent excavations by wolves. No wolf scats or other evidence of wolf presence were found. Cabin visitor logs contained no mention of wolf encounters for more than a decade. At Stordal landing strip, the most recent sighting of wolf was recorded in 1998, at Loch Fyne in 2000 and at Myggbukta in 2001.
Twenty years of data (1979-1998) showed that patrols travelled on average 1459 linear $\mathrm{km}(\mathrm{SD}=308$; range $=$ 755-2027) each winter in the Hold with Hope area. Military sightings revealed that a wolf pack had not been reported observed since March 2000, when a pack of three wolves was seen on the sea ice, and no evidence of wolves was reported for more than six years, from December 2000 until February 2007, when a single presumed wolf track was found near Loch Fyne. After 2007 and up until our arrival, no evidence of wolf presence was reported by the military despite substantial effort. Thus, for 17 years, 2001-2018, the only evidence of wolf reported by the military in this historically important core area was a single presumed wolf track.

Despite the unexpectedly short duration of fieldwork in Hold with Hope, I decided against returning the following summer because of the substantial effort by military patrols each winter and because indicators of wolves, when present, were well understood from surveys I conducted during five previous summers. Large declines may be easy to detect with only a single site visit (Field et al. 2005). During 1980-2001, wolves 
were sighted in Hold with Hope during at least 18 of 22 years (Fig. 2).

\section{Germania Land}

In response to my inquiries in July 2017 and August 2019, the manager of the Danmarkshavn weather station stated that the most recent sighting by station staff of a wolf occurred in May 2015, when a single animal arrived from the north, following a military patrol (P.-E. Nissen, Greenland TelePost, pers. comm.). He was not aware of any sightings of a wolf pack in the area despite having been working there since 2003. According to the weather station manager, sled dogs were kept tethered outdoors on the station area, and the open station dump was used for food scraps until 2005. Military data provided evidence that the most recent sighting of a wolf was made by patrols in 2002. Data from all other sources, 1979-2002, showed that wolves had been sighted in Germania Land during at least 16 of 24 years (Fig. 2).

\section{Region-wide sightings by military patrols}

Average military patrol effort in the north-east Greenland wolf range, 1979-2018, was $13590 \mathrm{~km}$ per year $(\mathrm{SD}=3426$; range $=8244-20425)$. I isolated 68 sightings of wolves in north-east Greenland from military data in the period 1980-2018 (data for 2003 were unavailable).
There were no sightings in north-east Greenland during patrols in 1979 , but there was a sighting made by civilians that year. The last sighting of a wolf pack occurred in 2000. Thereafter, sightings of single wolves were reported in 2001, 2002 and 2012.

Military data at the regional scale showed that the number of wolves/1000 km of patrol peaked in 1996 and then began a precipitous decline until 2001, when only a single wolf was sighted (Fig. 3). This suggests that the population was virtually eliminated in four years, consistent with a "sudden death" scenario. However, at the scale of the local area, using data from all sources, evidence points towards a longer decline. In Germania Land, wolf abundance was dramatically reduced as early as 1992 when only one wolf was sighted, and there was no evidence that abundance recovered to previous levels during the following 26 years (Fig. 2). In Jameson Land, abundance remained low but consistent from colonization around 1982 through an apparent local high in 1996 before disappearing sometime after 1998 (Fig. 2). In Hold with Hope, abundance reached a maximum in 1992 and declined thereafter, but a small pack was active as late as 2000, disappearing after 2001 (Fig. 2).

In north Greenland, 75 sightings of wolves, including packs, by military patrols, 1979-2018, provided evidence of a small wolf population there (Fig. 4). This population comprised up to 32 wolves during favourable years (Marquard-Petersen 2009).

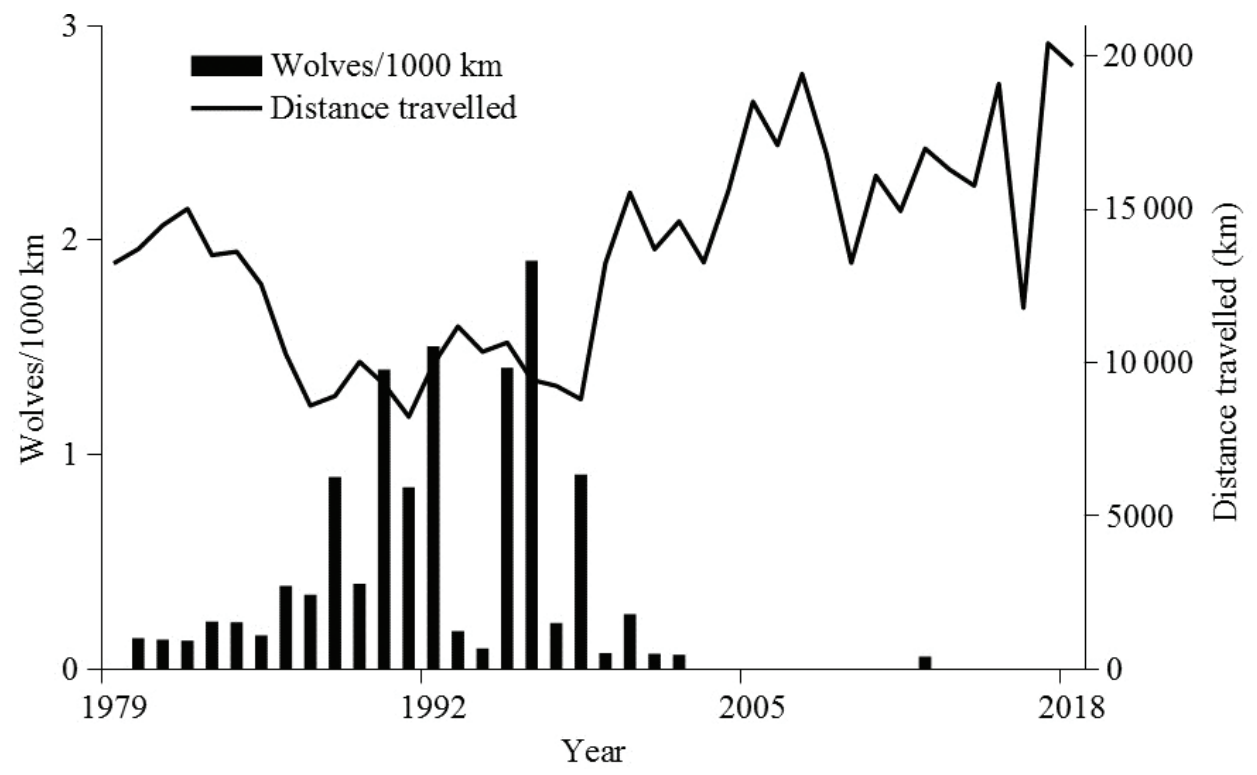

Fig. 3 The decline on a regional scale. Number of wolves seen per $1000 \mathrm{~km}$ of surface travel by Danish military patrols in winter, north-east Greenland, 1979-2018, except 2003 (no sighting data) and distance travelled. Notice the near absence of sightings of wolves after 2002 despite continued, high effort. The data point from 2012 represents a single wolf, which in all likelihood was the animal euthanized by gunshot in January 2013 after conflicts with tethered sled dogs. 


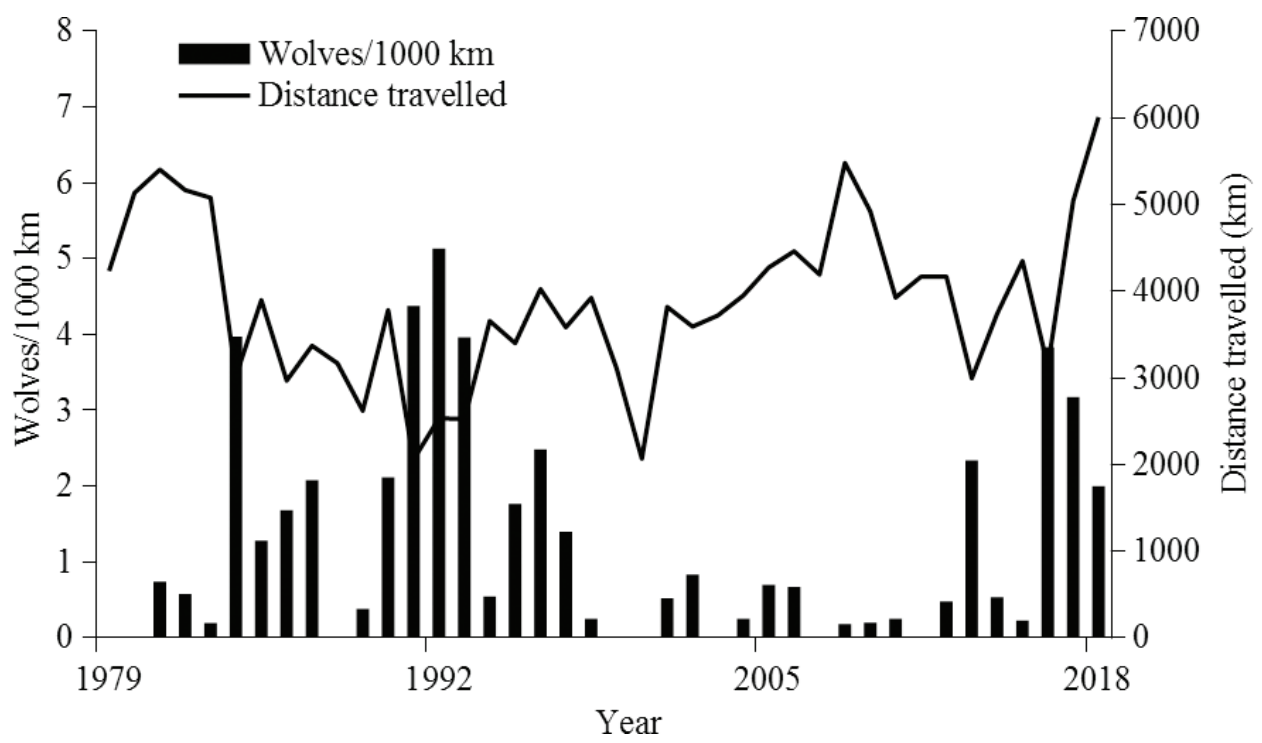

Fig. 4 Number of wolves seen per 1000 km of surface travel by Danish military patrols in winter, north Greenland, 1979-2018, except 2003 (no sighting data). Notice the increase in number of wolves reported since 2012, which could produce surplus individuals for recolonization of north-east Greenland. This figure also provides evidence that wolves, when present, will be detected by patrols during most years.

\section{Discussion}

This study investigated wolf occurrence in all areas of north-east Greenland known to be distributional core areas but found no recent evidence of occupancy by packs or single wolves, consistent with my prediction that a population crash had occurred. The data provided evidence of a collapse on both local and regional scales, with one pack disappearing in the early 1990s and the remaining packs in the late 1990s. Sightings of wolf packs by patrols ceased after 2000 , and only a few intermittent sightings of single wolves were reported thereafter, indicating that there was no longer a viable wolf population. Continued high patrol effort post-2000, without regular sightings of wolves, provided compelling evidence that the observed decline was real as opposed to effort-related.

There was no evidence that wolves of this population took up residence in other areas. Despite the remoteness of the region and limited human presence, such movement would likely have been detected for three reasons. First, geographical coverage by patrols was extensive, and their effort on land and sea ice in north-east Greenland was both major ( $\geq 9562 \mathrm{~km} /$ winter) and sustained (conducted every fall and spring). Wolf packs, being territorial, would almost certainly have been detected by patrols travelling repeatedly through a territory, though perhaps not every winter on account of extraterritorial forays, bad visibility, poor snow-tracking conditions and other factors, but likely over a few years, as shown by the data presented here. Second, patrols were travelling by dog team and domestic dogs attract Arctic wolves (Tener 1952; Grace 1976; Gray 1995; Miller 1993; MarquardPetersen 2011a). Third, these wolves likely travel over vast areas in search of food, as evidenced by a single GPS collar deployed in the Canadian High Arctic (Mech \& Cluff 2011). My own tracking experience involves following a pack in Peary Land, north Greenland, in May 1995 by snowmobile; these wolves travelled $105 \mathrm{~km}$ in 24 hours. Extensive travel by wolves results in increased detection probability. There were no other factors known to me that could have led to a false conclusion that wolves had abandoned this region. Despite their shortcomings in regard to statistical analysis, data from military ground patrols continue to be the most useful index to the relative abundance, distribution and trend of this remote wolf population. It is also the principal financially realistic, long-term monitoring method in this vast, uninhabited region.

\section{Hold with Hope}

This area had a $>50$-year history as the most important wolf habitat in the region, with the highest known pup production, most frequent reproduction and largest contemporary pack size (Marquard-Petersen 2008, 2009, 2012). Despite this record, we found no signs of recent wolf presence. Because Badlanddalen had outstanding tracking conditions, wolf tracks would have been visible had wolves been present. In some locations in this valley, 
tracks can be detected for at least a year. I have observed my own footprints in mud in Hold with Hope 12 months after I walked there. Our specialized wolf surveys in previous years had indicated that Badlanddalen served as a central link between the Hold with Hope peninsula, Gauss Peninsula and Hudson Land, as evidenced by wolf tracks crisscrossing the valley. If wolves had been present in this core area, Badlanddalen would be the most likely place to locate evidence of that presence.

No wolf scats were found at known den sites, which was important for two reasons. First, during den surveys in prior years, I systematically collected and removed all scats to facilitate an assessment in future years of whether wolves had visited the sites during my absence. Second, as a result of a "scat longevity test," in which I monitored the rate of decomposition of a wolf scat in this area, I have photographic and video evidence that a scat can lie largely intact on the tundra in this environment for at least six years. Therefore, the absence of wolf scats at den sites in 2014 was evidence that the sites had not been used by wolves since 2008 and likely longer. Furthermore, wolf presence that produced new excavations would have been readily apparent, because I recorded numbers and locations of burrows during surveys and because my prior fieldwork had established that plant recolonization of soil excavated by wolves takes several years. Although wolves could have been denning elsewhere, the destroyed, abandoned state of known den sites indicated that a pack had not frequented the area for many years. A pack may have been absent from Hold with Hope since 2000, given that the last military sighting occurred that year. Moreover, visitor logs contained no mention of single wolves after 2001.

It was outside the scope of this study to undertake an analysis of all possible factors in the disappearance of wolves from this historically important wolf habitat. Such work has been conducted on the wolf population in north-east Greenland exterminated by ca. 1939 (Marquard-Petersen 2012) and was difficult to do credibly in this vast, remote and largely uninhabited region because of an absence of data on possibly relevant factors. Nevertheless, it was noteworthy that the Hold with Hope pack reached a contemporary maximum of nine wolves in 1992, a pack that large had not been reported in northeast Greenland in 66 years (from Marquard-Petersen 2007). It was also of potential importance that the last known case of reproduction occurred three years later (1995), when a single pup was sighted-the lowest, known pup production in this core area (MarquardPetersen 2008). The key to the disappearance of wolves from Hold with Hope, therefore, might lie in the population maximum of 1992, and the impact this unusual population growth may have had on ungulate prey resources and, ultimately, on the ability of the pack to sustain itself. No systematic work has been conducted on the local muskox population to investigate this possibility, but in August 1996, two Danish muskox biologists wrote in a cabin visitor log that they had seen a surprisingly small number of muskoxen in the area (Aastrup $\delta$ Riget in Stordal airstrip cabin $\log$ ). We observed exceedingly few muskoxen during our 2014 wolf survey relative to our surveys in the early 1990s, when muskox densities of up to 23 muskoxen/100 $\mathrm{km}^{2}$ were observed (MarquardPetersen 1998). Geese of various species were also absent, in contrast to the 1990s, when they constituted the secondary prey of these wolves (Marquard-Petersen 1998).

\section{Jameson Land}

The pack in this area seems to have disappeared sometime after 1998. This estimate was conservative and subject to greater uncertainty than in other areas because of the absence of military patrols. The collapsed and overgrown state of the wolf den, without any scats present, indicated that the site had not been used by wolves in years. The organized state of muskox skeletal remains throughout Jameson Land also provided evidence of wolf absence, because scavenging wolves tend to carry away parts of ungulate carcasses (Haynes 1982).

Wolves disappeared from Jameson Land despite the presence of substantial ungulate prey resources. Repeated aerial surveys have suggested that 2800-4700 muskoxen inhabited this area, equal to an overall density of 19-44 muskoxen $/ 100 \mathrm{~km}^{2}$, with an average of 28 muskoxen/ 100 $\mathrm{km}^{2}$ (Aastrup 2000). Given this prey abundance, a maximum known pack size of only three wolves over 14 years was difficult to explain. Population densities of many species tend to be lower along the margin of their geographic range (Gaston 1994; Brown et al. 1995; Lomolino \& Channell 1995). Jameson Land was situated at the extreme limit of the distribution of the Arctic wolf, and perhaps this accounted for the apparent low wolf abundance. A consistently small pack size would have left this pack vulnerable to extinction due to stochastic events: if one wolf died of natural causes and another was shot, the pack would be eliminated, assuming no immigrants. Wolves could be legally hunted in Jameson Land yearround, with no bag limit, but hunting appeared insignificant in terms of numbers, as only two wolves were reported killed (Marquard-Petersen 2008).

\section{Germania Land}

The pack in this area reached a maximum in 1988, when pups were observed (Maagaard 1988), and then it disappeared sometime after 1991. Since then, only single 
wolves have been periodically reported. The absence of sightings of a pack at the Danmarkshavn weather station was particularly revealing, because the open dump served as an easy food source until 2005. The presence of tethered sled dogs would also have been an important attractant. If a pack had inhabited Germania Land after 1991, these wolves would likely have visited Danmarkshavn and eventually been detected.

The report of a relatively large pack of six wolves was intriguing, because ungulate prey resources were extraordinarily limited even by north-east Greenland polar desert and semi-desert standards. In 1990, between 175 and 215 muskoxen were believed to be present (Boertmann et al. 1992), equal to a density of 2.7-3.3 muskoxen/100 $\mathrm{km}^{2}$ of land area. Germania Land was therefore the most marginal of the three distributional core areas in northeast Greenland, and it was also the first to lose a viable pack structure.

Given a local muskox population perhaps as small as 175 animals, it is not surprising that wolves disappeared from Germania Land, but rather that they were able to persist as long as they did and even produce pups, indicating either that estimates of prey numbers were too low or that wolves were able to acquire sufficient food resources elsewhere, or both. Alternatively, periodic reports of wolves arriving from the north (MarquardPetersen 2011 a) could indicate that some wolves observed in this area were not local residents but were transients on the way south, thus inflating occupancy rates. The pack that inhabited Germania Land in the late 1980s appears to have been struggling unsuccessfully to colonize the area. Colonization attempts have been reported from Isle Royale (Peterson \& Page 1988) and Alaska (Mech et al. 1998) and were suspected in north-western Minnesota (Fritts \& Mech 1981). It is not unusual for wolf packs to flourish for a few years and then cease to exist or for territories to be vacated (Fritts \& Mech 1981; Mech et al. 1998; Adams et al. 2008).

\section{Region-wide findings}

It is unclear why the north-east Greenland wolf population never increased beyond about 23 wolves, despite largely inhabiting a national park with full legal protection and a large ungulate population estimated at 826010945 muskoxen south of $79^{\circ} 30^{\prime} \mathrm{N}$ (Boertmann et al. 1992). Around 2002, the population declined and disappeared 23 years after being founded. But numerical estimates of prey numbers may not adequately reflect the survival challenges facing these wolves. North and northeast Greenland may be the most impoverished wolf habitat in physiographic North America, containing comparatively few prey species, ungulate prey spread across a very large area and $8.5 \%$ and $2.6 \%$ of the ungulate prey biomass available to wolves in interior Alaska and in north and eastern Minnesota, respectively (Marquard-Petersen 2009). Four wolves killed in Germania Land in January-March 1908 were described as having "emaciated, almost skeleton-like bodies" weighing 20.5-29 kg (Manniche 1910: 63), indicating the very difficult conditions faced by wolves in this area during some winters.

Little is known about the presence or absence in north-east Greenland of factors that have contributed to wolf population declines elsewhere. Hunting appears to be unlikely to be important given legal protection in the national park where most of the wolf population occurred. Nonetheless, the cumulative adverse effect of killing "nuisance" wolves might be important. During the period 1979-2018, at least six wolves were reported killed in north-east Greenland; four of these were shot inside the national park after conflicts with humans or sled dogs (Marquard-Petersen 2008 and unpubl. data) The combined wolf population in north and north-east Greenland occurred largely as singletons and pairs (Marquard-Petersen 2009), providing compelling evidence that shooting even one wolf potentially has population-level impacts by eliminating the possibility of future pup production in that area, at least temporarily. The likelihood of replacement individuals through immigration into north-east Greenland is believed to be low because of geographical isolation and vast distances of poor wolf habitat between inhabitable areas of north-east and north Greenland (Marquard-Petersen $2011 \mathrm{a})$. Known reproduction was infrequent and limited to no more than three pups per litter (MarquardPetersen 2008), indicating that replacement of shot wolves through pup production would not necessarily happen quickly. Thus, in north-east Greenland, lethal control as a wildlife management technique increased the likelihood of local extinctions of wolves by exacerbating the existing vulnerability to extinction brought about by low fecundity, a small population size at low densities, and a population concentrated in only three widely separated distributional core areas (MarquardPetersen $201 \mathrm{lb}$ ).

Although a viable wolf population no longer exists in north-east Greenland, lone wolves will continue to occur there sporadically, as they disperse into the region from the north. In 2012, a military patrol reported that a wolf followed them from north Greenland, and in 2015 staff at the Danmarkshavn weather station observed the arrival of a single wolf from the north. The long-term survival of lone wolves is doubtful. First, reports of single wolves bringing down adult muskoxen are rare. I know of only one such case (Gray 1970). Second, no 
alternate ungulate prey is available to sustain lone wolves during the long and hard polar winters. Thus, the future of the Arctic wolf in this part of its range looks uncertain but there is a precedent. After extermination of the north-east Greenland wolf population during the 1930s, it was 40 years before a male and a female succeeded in penetrating into the region and establishing a new population (Marquard-Petersen 201la). In the absence of management intervention, it could be decades before this species returns to north-east Greenland at a meaningful level.

\section{Management and conservation recommendations}

The Greenland home rule government could take action to improve protection for the few remaining wolves in north Greenland while increasing chances of survival for occasional dispersers into north-east Greenland. This would include (1) discontinuing the shooting of "nuisance" wolves as a wildlife management technique, while encouraging people to report illegal shootings and following up such reports with investigations and legal consequences; (2) changing the status of the Arctic wolf from "Vulnerable" (Boertmann \& Bay 2018) to "Endangered" on the grounds of the loss of the north-east Greenland population, the low number $(\leq 32)$ of wolves remaining in north Greenland, the risks associated with low effective population size, low fecundity and demographic stochasticity, and the fact that little is known about whether this population receives immigrants from Canada; (3) promoting research to identify root causes of why wolves are being shot inside the national park and developing effective counter-measures in collaboration with stakeholders to minimize conflicts, including non-lethal deterrence methods; (4) in national park regulations, prohibiting feeding of wolves and providing educational outreach to visitors as a part of the mandatory permitting process for travel to remote areas (offering food for photographic opportunities has had a tragic ending for a number of wolves [Marquard-Petersen 2008]); (5) implementing and enforcing year-round protection for wolves outside the national park in Jameson Land and Liverpool Land to improve the survival prospects of dispersers that reach these areas that are exempt from legal protection status (in accordance with Greenland home rule regulation number 9 of 5 May 1988); (6) prohibiting open garbage dumps, which attract wolves and lead to conflicts with humans (Miller 1993; Maagaard 1994; Gray 1995). At an outpost in 2014, we observed unburnt garbage that wind had scattered onto nearby tundra despite the prohibition of littering in paragraph 29 of the Northeast Greenland National Park regulations of 17 June 1992.

\section{Conclusion}

The small, isolated wolf population that managed to establish itself in north-east Greenland in 1979, about 40 years after an original wolf population had been exterminated, has disappeared. With this decline, about $41.8 \%$ of wolves on the island are gone. This finding should raise conservation concerns for the last wolves of Greenland.

\section{Acknowledgements}

This work is the product of the combined efforts of many people not directly connected to this long-term wolf research programme. I acknowledge the contributions of the following: I. Gade-Jørgensen and R. Stagegaard of Denmark, for conducting a wolf survey in Jameson Land in 1998, which alerted me to the locations of possible den sites; M. Lea of the UK, for assistance with obtaining funding that proved critical for completion of the fieldwork; K. Hansen and L. Brøndsel of the Danish Armed Forces' Joint Arctic Command, for invaluable logistical assistance in 2014; P.-E. Nissen of Greenland TelePost, for information from the Danmarkshavn weather station; $\mathrm{T}$. Hansen of the Joint Arctic Command, for obtaining sightings of wolves by military patrols and information on distances travelled; and the Sirius special forces unit of the Danish Armed Forces, for continuing their tradition of data collection in the advancement of science. I also wish to thank three anonymous reviewers who commented on drafts of the manuscript.

\section{Disclosure statement}

The author reports no potential conflict of interest.

\section{Funding}

The author wishes to acknowledge the Gino Watkins Memorial Fund, Scott Polar Research Institute, Cambridge, England, for providing financial assistance that proved instrumental in the completion of the fieldwork.

\section{References}

Aastrup P. 2000. Muskox population studies in Greenland. PhD thesis, National Environmental Research Institute, Copenhagen.

Adams L.G, Stephenson R.O., Dale B.W., Ahgook R.T. \& Demma D.J. 2008. Population dynamics and harvest characteristics of wolves in the central Brooks 
Range, Alaska. Wildlife Monographs 170, 1-25, doi: 10.2193/2008-012.

Boertmann D. \& Bay C. 2018. Grønlands Rødliste 2018. (Greenland Red List 2018.) Aarhus, Denmark: Aarhus University.

Boertmann D., Forchhammer M., Olesen C.R., Aastrup P. \& Thing H. 1992. The Greenland muskox population status 1990. Rangifer 12, 5-12, doi: 10.7557/2.12.1.1013.

Brown J.H., Mehlman D.W. \& Stevens G.C. 1995. Spatial variation in abundance. Ecology 76, 2028-2043, doi: $10.2307 / 1941678$.

Field S.A., Tyre A.J. \& Possingham H.P. 2005. Optimizing allocation of monitoring effort under economic and observational constraints. Journal of Wildlife Management 69, 473-482, doi: 10.2193/0022-541X(2005)069[0473:OAOMEU]2.0.CO;2.

Fritts S.H. \& Mech L.D. 1981. Dynamics, movements, and feeding ecology of a newly protected wolf population in northwestern Minnesota. Wildlife Monographs 80. Bethesda, MD: Wildlife Society.

Gaston K.J. 1994. Rarity. Population and community biology series 13. New York: Chapman \& Hall.

Grace E.S. 1976. Interactions between men and wolves at an Arctic outpost on Ellesmere Island. Canadian FieldNaturalist 90, 149-156.

Gray D.R. 1970. The killing of a bull muskox by a single wolf. Arctic 23, 197-199, doi: 10.14430/arctic3172.

Gray D.R. 1995. The wolves of Alert. Final report for Ellesmere Island National Park Reserve, Parks Canada, Dept. of Canadian Heritage. Metcalfe, ON: Greyhound Information Services.

Haynes G. 1982. Utilization and skeletal disturbances of North American prey carcasses. Arctic 35, 266-281, doi: 10.14430/arctic2325.

Krebs C.J. 1999. Ecological methodology. New York: Addison Wesley Longman.

Lomolino M.V. \& Channell R. 1995. Splendid isolation: patterns of geographic range collapse in endangered mammals. Journal of Mammalogy 76, 335-347, doi: $10.2307 / 1382345$.

Maagaard L. 1988. Ynglefund af polarulv (Canis lupus arctos) ved Danmarkshavn Nordøstgrønland. (Evidence of wolf [Canis lupus arctos] reproduction at Danmarkshavn, north-east Greenland.) Flora og Fauna 94, 89-92. (Includes English summary.)

Maagaard L. 1994. Ulvevandringer. (Wolf migrations.) Tidsskriftet Grønland 2, 49-61.

Manniche A.L.V. 1910. The terrestrial mammals and birds of north-north-east Greenland-biological observations. Meddelelser om Grønland 45. Copenhagen: C. A. Reitzels Forlag.

Marquard-Petersen U. 1998. Food habits of Arctic wolves in Greenland. Journal of Mammalogy 79, 236-244, doi: $10.2307 / 1382859$.

Marquard-Petersen U. 2007. Ecology of the High Arctic wolf in northeast Greenland, 1899-1998. PhD thesis, University of Copenhagen.
Marquard-Petersen U. 2008. Reproduction and mortality of the High Arctic wolf, Canis lupus arctos, in northeast Greenland, 1978-1998. Canadian Field-Naturalist 122, 142-152, doi: 10.22621/cfn.v122i2.573.

Marquard-Petersen U. 2009. Abundance, social organization, and population trend of the Arctic wolf in north and northeast Greenland during 1978-1998. Canadian Journal of Zoology 87, 895-901, doi: 10.1139/Z09-078.

Marquard-Petersen U. 201 la. Invasion of eastern Greenland by the High Arctic wolf Canis lupus arctos. Wildlife Biology 17, 383-388, doi: 10.2981/11-032.

Marquard-Petersen U. $201 \mathrm{lb}$. Insular and disjunct distribution of the Arctic wolf in Greenland, 19781998. Polar Biology 34, 1447-1454, doi: 10.1007/ s00300-011-1002-5.

Marquard-Petersen U. 2012. Decline and extermination of an Arctic wolf population in northeast Greenland, 1899-1939. Arctic 65, 155-166, doi: 10.14430/arctic4197.

Mech L.D., Adams L.G., Meier T.J, Burch J.W. \& Dale B.W. 1998. The wolves of Denali. Minneapolis, MN: University of Minnesota Press.

Mech L.D. \& Cluff H.D. 2011 . Movements of wolves at the northern extreme of the species' range, including during 4 months of darkness. PLoS One 6, e25328, doi: 10.1371/ journal.pone.0025328.

Miller F.L. 1978. Interactions between men, dogs and wolves on western Queen Elizabeth Islands, Northwest Territories, Canada. The Musk-Ox 22, 70-72.

Miller F.L. 1993. Status of wolves in the Canadian Arctic Archipelago. Technical Report Series 173. Edmonton, AB: Canadian Wildlife Service Western and Northern Region.

Miller F.L. \& Reintjes F.D. 1995. Wolf-sightings on the Canadian Arctic Islands. Arctic 48, 313-323, doi: 10.14430/arctic1 253.

Miller F.L. \& Russell R.H. 1977. Unreliability of strip aerial surveys for estimating numbers of wolves on western Queen Elizabeth Islands, Northwest Territories. Canadian Field-Naturalist 91, 77-81.

Pecl G., Araujo M.B., Bell J.D., Blanchard J., Bonebrake T.C., Ching Chen I., Clark T.D., Colwell R.K., Danielsen F., Evengard B. \& Robinson S.A. 2017. Biodiversity redistribution under climate change: impacts on ecosystems and human well-being. Science 355, eaai9214, doi: 10.1126/science.aai9214.

Peterson R.O. \& Page R.E. 1988. The rise and fall of Isle Royale wolves, 1975-1986. Journal of Mammalogy 69, 89-99, doi: 10.2307/1381751.

Riewe R.R. 1975. The High Arctic wolf in the Jones Sound region of the Canadian High Arctic. Arctic 28, 209-212, doi: $10.14430 / \operatorname{arctic} 2835$.

Tener J.S. 1952. A preliminary study of the muskoxen of Slidre Fiord District, Fosheim Peninsula, Ellesmere Island. M.Sc. thesis, University of British Columbia.

Vors L.S. \& Boyce M.S. 2009. Global declines of caribou and reindeer. Global Change Biology 15, 2626-2633, doi: $10.1111 / \mathrm{j} .1365-2486.2009 .01974 . x$ 